\title{
Membrana de PLDLA-TMC como Protetor na Regeneração do Tendão Calcâneo. Estudo in Vivo em Coelhos
}

\author{
Julia Rezende Duek, Mayara Lopes Riquetto, Daniel Contri Jesus, João José Sabongi Neto, \\ Maria Lourdes Peri Barbo, Eliana Aparecida de Rezende Duek, Adriana Cristina Motta \\ Laboratório de Biomateriais, Pontifícia Universidade Católica de São Paulo - PUC-SP, Sorocaba, SP, Brasil
}

\begin{abstract}
Resumo: Um dos maiores problemas da cirurgia restauradora dos tendões flexores é evitar a formação de aderências, pois limita seu deslizamento. Assim, é muito desejável que a cicatrização ocorra o mais rápido possível, restaurando a capacidade de deslizamento dos tendões, sem limitações dos movimentos. O objetivo deste trabalho foi analisar a resistência do Tendão calcâneo, utilizando membrana de PLDLA-TMC como protetor da aderência dos tecidos adjacentes após implantes em coelhos New Zeland. Foram utilizados 20 coelhos, divididos em dois grupos, os quais foram submetidos à secção do tendão calcâneo e posterior sutura com técnica de Kessler modificada. No grupo A, logo após sutura o animal foi sacrificado e o tendão foi enviado para ensaio mecânico. Já no grupo B, após três semanas, os animais foram sacrificados e o material foi submetido à análise histológica. Os resultados obtidos a partir do ensaio mecânico mostraram melhora nos valores da resistência à tração dos implantes com a membrana, comparados aos apenas suturados. Na cicatrização da lesão, ocorreu melhor organização das fibras colágenas quando foi utilizado o polímero PLDLA-TMC, além de uma menor aderência cicatricial. Conclui-se que a membrana de PLDLA-TMC é promissora na reparação de lesões tendíneas.
\end{abstract}

Palavras-chave: Terpolimeo, PLDLA-TMC, tendão, reparo.

\section{Membrane PLDLA-TMC as Shield Regeneration in the Calcaneal Tendon. Study in Live Rabbits}

\begin{abstract}
The most common problem in reconstructive surgery of the flexor tendons is prevent adhesion formation by limiting its movement. Thus, it is very desirable that healing occurs as quick as possible, restoring tendons sliding capability, without limitation of movement. The objective of this study was to analyze the strength of the Achilles tendon, using PLDLA-TMC membrane as protector of the adhesion of adjacent tissues implanted in New Zealand rabbits. Twenty rabbits were used, divided into two groups, which were submitted to the section of the Achilles tendon and posterior suture with modified Kessler technique. In group A, after suturing, the animals were sacrificed and the tendon was sent for mechanical tests. In group B, after three weeks, the animals were sacrificed and the material was subjected to histological analysis. The results of the mechanical tests showed improvement in the values of the tensile strength of the implants with the membrane, compared to the sutured ones. In the injury healing process, better organization of collagen fibers occurred when the PLDLA-TMC polymer was used, and a smaller scar tissue adhesion was developed. In conclusion, the PLDLA-TMC membrane is promising in the repair of tendon injures.
\end{abstract}

Keywords: Terpolymer, PLDLA-TMC, tendon, repair.

\section{Introdução}

Os tendões constituem a unidade do sistema musculoesquelético que transmite a força do músculo ao osso ${ }^{[1,2]}$. Sua arquitetura permite o suporte de grandes tensões, e a transmissão da força gerada durante a contração muscular ao osso, para a realização dos movimentos $^{[3]}$.

O tendão é constituído por fibroblastos e intermediado por fibras colágenas (30\%), por fibras elásticas $(2 \%)$ e o restante por água ${ }^{[4]}$. São aparentemente pouco vascularizados, porém suficientemente nutridos, para promoverem o processo de reparação, que se desenvolve a partir de moléculas de colágeno no período de 6 a 14 dias. Inicialmente, as fibras são desordenadas, porém, de acordo, com as solicitações de tração, tornam-se paralelas e passam a apresentar ligações cruzadas entre elas ${ }^{[5]}$.
As funções fisiológicas dos tendões consistem em transmitir a força muscular que atuará no osso, armazenar energia propulsora, possibilitar que o músculo não atrapalhe o movimento articular, funcionar como um dissipador de energia e resistir a forças de tensão na flexibilidade.

Após uma lesão, o processo de reparo do tendão pode ser dividido em três fases distintas que são diferenciadas por uma cascata de eventos celulares e bioquímicos. O objetivo é promover o restabelecimento das fibras tendíneas e o mecanismo de deslizamento com as estruturas adjacentes ${ }^{[3]}$. As três fases sequenciais são denominadas inflamatória, proliferativa ou fibroblástica e de remodelação. A primeira fase ocorre imediatamente após a lesão; já a seguinte, inicia-se aproximadamente no quinto dia e a remodelação em aproximadamente quatro

Autor para correspondência: Eliana Aparecida de Rezende Duek, Departamento de Ciências Fisiológicas, Centro de Ciências Médicas e Biológicas - CCMB, Pontifícia Universidade Católica de São Paulo - PUC-SP, Praça Dr. José Ermírio de Moraes, 290, Jd. Vergueiro, CP 1570, CEP 18030-095, Sorocaba, SP, Brasil, e-mail: eliduek@pucsp.br 
a oito semanas, caracterizando-se, principalmente, pelo realinhamento do colágeno ao longo da linha de força do tecido $^{[6]}$

Um dos maiores problemas da cirurgia restauradora dos tendões flexores é evitar a formação de aderências, pois limita seu deslizamento. Assim, é muito desejável que a cicatrização ocorra o mais rápido possível, restaurando a capacidade de deslizamento dos tendões, sem limitações dos movimentos, o que representa um grande desafio para pesquisadores da área. Estudos recentes desenvolvidos por Zhao et al. ${ }^{[7]}$ comparam o reparo de tendões, em duas situações: empregando ou não uma membrana de colágeno no revestindo do tendão lesionado, sendo observado menor aderência no grupo onde foi empregado a membrana como revestimento. Em outro trabalho desenvolvido por Gigante et al. ${ }^{[8]}$ também fica evidente a importância da presença de uma membrana no revestimento de tendão visando diminuir o problema da adesão.

Os protocolos de tratamento para pacientes com ruptura aguda do Tendão calcâneo são constantemente modificados. Tanto terapias cirúrgicas e não cirúrgicas são seguidas por imobilização com gesso ou tala removível. Entretanto, apesar de severos estudos, não há consenso quanto ao melhor protocolo de tratamento. Metanálises geralmente confirmam que a taxa de nova ruptura da lesão, é maior em pacientes tratados com terapia não cirúrgica $(12,6 \%)$ que em pacientes tratados cirurgicamente $(3,5 \%)$, mas o risco varia consideravelmente em estudos anteriores $^{[9]}$.

A aplicação de membranas de Poli-ácido-glicólico auto reforçado (SR-PGA) no reparo da ruptura do Tendão calcâneo de coelhos tem sido avaliada, através de métodos qualitativos e histoquantitativos. O propósito dos estudos foi investigar os efeitos da imobilização comparados com a não imobilização no processo de biodegradação, interação entre implante e tecido, e formação de cicatriz tecidual após envolver completamente o Tendão calcâneo do coelho com membrana de SR-PGA.

Produtos específicos para redução da aderência tissular já podem ser encontrados no mercado, OrthoWrap ${ }^{\circledR}$, consiste em um polímero biorreabsorvível feito de Poli (L -co- D, L ácido lático) (PLA), utilizado na forma de membrana, a qual envolve completamente a área lesionada do tendão ${ }^{[10]}$. $\mathrm{O}$ emprego de membranas biorreabsorvíveis tem sido amplamente documentado na literatura em cirurgias de reparo de tendão ${ }^{[11]}$.

Os polímeros sintéticos do tipo biorreabsorvíveis representam uma escolha atrativa na engenharia tecidual, pois esse tipo de material pode ter, durante seu processo de síntese, suas propriedades delineadas, em termos de propriedades mecânicas, macroestrutura e perfil de degradação ${ }^{[12]}$. O desenvolvimento de copolímeros ou terpolímero com alta elasticidade e perfil controlável de degradação também apresenta um potencial de uso na área da engenharia tecidual bastante promissor.

Dessa forma, visando um aumento da elasticidade no copolímero Poli (L-co-DL- ácido lático), foi empregado para o estudo em questão, um terpolimero sintetizado no laboratório de Biomateriais da PUC, que apresenta em sua estrutura segmentos de 1,3 trimetileno carbonato, TMC, um policarbonato alifático elastomérico, de comprovada biocompatibilidade ${ }^{[12]}$. A sigla deste terpolimero de poli (L-co-D,L ácido lático-co-TMC), é PLDLA-TMC.

O objetivo deste estudo foi analisar a resistência do Tendão calcâneo em coelhos, utilizando lâmina de PLDLA-TMC como proteção, além da qualidade histológica da cicatriz e avaliação da aderência aos tecidos adjacentes.

\section{Materiais e Métodos}

\section{Preparo e caracterização das membranas}

O terpolimero PLDLA-TMC de massa molar empregado foi sintetizado no laboratório de Biomateriais da PUC de acordo com Motta (INPI 020110049277) ${ }^{[13]}$. Soluções de PLDLA - TMC 70/30 foram preparadas por diluição do copolímero em clorofórmio (Merck®) $(10 \% \mathrm{~m} / \mathrm{v})$ à temperatura ambiente de $25{ }^{\circ} \mathrm{C}$. Após completa dissolução do polímero, a solução foi vertida em um molde para evaporação do solvente. Após completa evaporação do solvente, as amostras foram secas a vácuo e armazenadas em um dessecador (Figura 1). Os filmes foram cortados nas dimensões de $1,5 \mathrm{~cm} \times 0,8 \mathrm{~cm} \times 80 \mu \mathrm{m}$ e lavados em água destilada para posterior implante no animal.

\section{Caracterização das membranas}

Cromatografia de permeação a gel (GPC)

Através da cromatografia de permeação em gel foram obtidos resultados de massa molar média em número $(\mathrm{Mn})$, massa molar em massa (Mw) e polidispersividade (IP) para cada copolímero sintetizado.

Calorimetria Exploratória Diferencial (DSC)

Aproximadamente $10 \mathrm{mg}$, da amostra foram aquecidas de 25 a $200{ }^{\circ} \mathrm{C} \mathrm{a} 5{ }^{\circ} \mathrm{C} / \mathrm{min}$ e logo após resfriadas a $30{ }^{\circ} \mathrm{C} / \mathrm{min}$ até $-50{ }^{\circ} \mathrm{C}$, sendo a seguir aquecidas até $200{ }^{\circ} \mathrm{C}$, sob purga de $\mathrm{N}_{2}$ em um equipamento Ta modelo MDSC291.

\section{Estudo in vivo - Implante das membranas}

Foram utilizados 20 coelhos albinos, Nova Zelândia, de ambos os sexos, com idade mínima de 90 dias, com peso variando entre $1700 \mathrm{~g}$ e $2200 \mathrm{~g}$. Os animais foram submetidos à anestesia geral por via intramuscular de

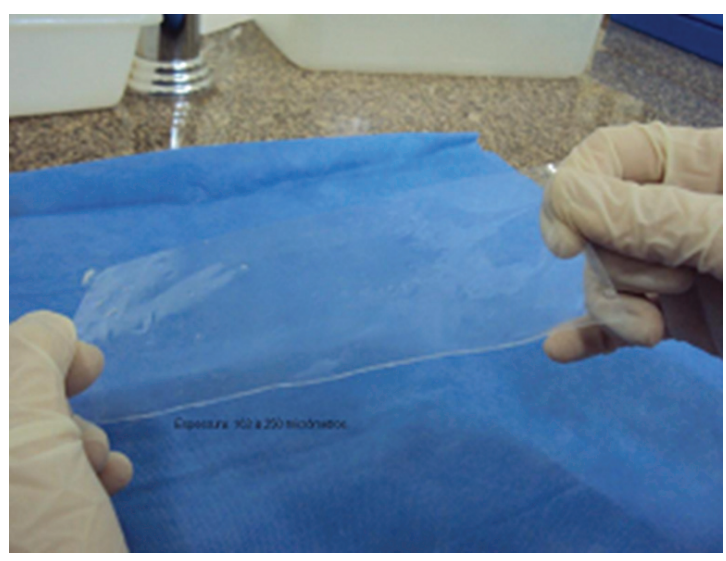

Figura 1. Foto da membrana a ser implantada. 
cloridrato de ketamina (30 $\mathrm{mg} / \mathrm{kg}$ de peso) associado a cloridrato de xilazina ( $5 \mathrm{mg} / \mathrm{kg}$ de peso). Antes da cirurgia, os animais permaneceram em jejum por 12 horas. Foi realizada tricotomia da pata traseira. Os coelhos foram posicionados em mesa cirúrgica apropriada, em decúbito ventral horizontal. A assepsia foi feita com solução de álcool iodado a 50\% aplicado com gazes estéreis.

$\mathrm{O}$ acesso foi feito através de uma incisão posterior, seguida de dissecção cuidadosa e hemostasia até visualização do Tendão calcâneo. Após a exposição, foi feita a secção completa do tendão com lâmina de bisturi $\mathrm{n}^{\circ} 15$, a uma distância de $1,7 \mathrm{~cm}$ de sua inserção. Em seguida, foi realizada a tenorrafia com a técnica de Kessler modificada, fazendo-se uso de fio de nylon 5.0 e 6.0 (Figura 2). Foi aplicada a membrana de PLDLA-TMC ao redor da área da tenorrafia, formando uma semi-cânula, envolvendo dois terços da circunferência do tendão, permitindo assim sua nutrição adequada (Figura 3). Esta membrana foi fixada com quatro pontos simples em cada extremidade. O término do implante deu-se através de limpeza com soro fisiológico $0,9 \%$, hemostasia e sutura da pele com ponto simples, utilizando-se nylon 4.0.

Todos os animais da amostra foram submetidos à mesma técnica cirúrgica. Na pata direita o procedimento cirúrgico descrito foi realizado por completo, e na pata esquerda foi realizada apenas secção e tenorrafia, pois foi utilizada como controle do estudo. Depois de finalizada a etapa cirúrgica os animais foram divididos em dois grupos, A e B, tendo cada grupo 10 coelhos. O grupo A, logo após o procedimento cirúrgico foi sacrificado e submetido a ensaio mecânico de tração, com a finalidade de verificar se haveria diferenciação, nas diferentes situações: tendão

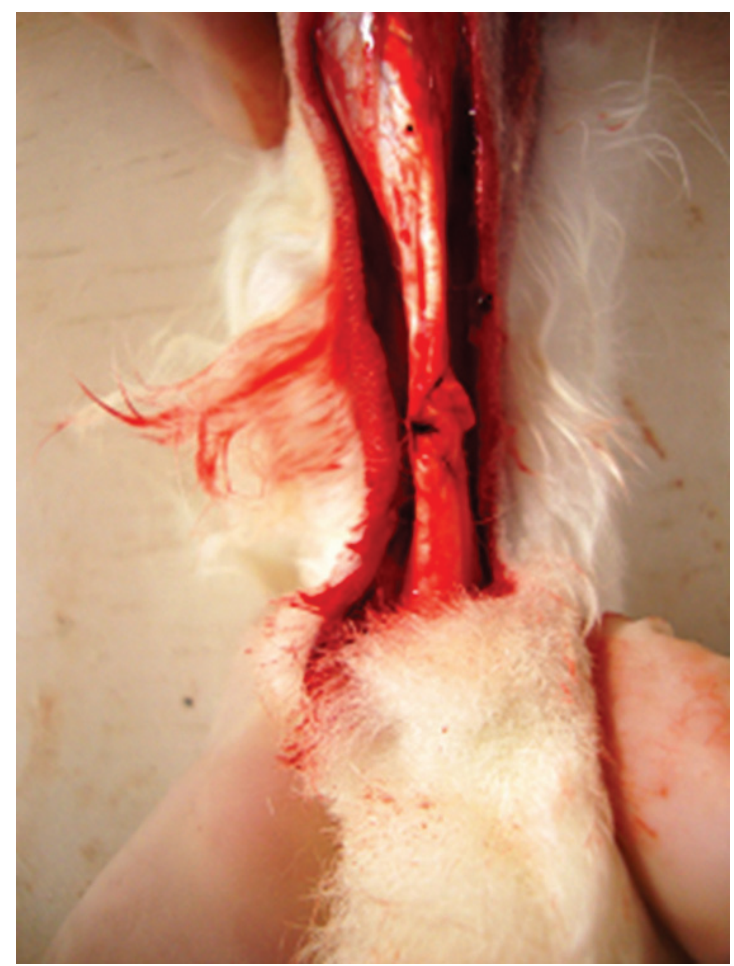

Figura 2. Aspecto macroscópico do tendão suturado sem o terpolímero PLDLA-TMC. somente suturado e tendão suturado e parcialmente envolvido com a membrana do PLDLA-TMC. Já o grupo $\mathrm{B}$, foi designado à análise histológica e os animais foram colocados no Biotério em gaiolas individuais suspensas e receberam ração comercial e água, sendo sacrificados após três semanas. Não foi utilizado nenhum método para imobilização das patas dos animais no pós-operatório.

\section{Ensaio mecânico de tração}

Após secção de seguimento dos tendões, que possuíam em média $13,01 \mathrm{~mm}( \pm 0,45)$ de comprimento por $0,28 \mathrm{~mm}( \pm 0,45)$ de espessura, eles foram suturados e submetidos ao ensaio mecânico de tração em um equipamento servo-hidráulico da Testar II, modelo 810, do fabricante MTS, célula de carga com capacidade de $1 \mathrm{KN}$ e velocidade de $50 \mathrm{~mm} \cdot \mathrm{min}^{-}$do Laboratório de Bioengenharia da Faculdade de Engenharia Mecânica. A máquina foi acoplada a um microcomputador com software responsável pelo comando do equipamento e pilotagem do gráfico força versus deformação. Foi construído gráfico força versus deformação e obtidos os seguintes parâmetros: força máxima, deformação na força máxima e ruptura. Foi estabelecido valor de referência e verificada a porcentagem de tendões que foi capaz de suportar uma carga maior ou igual a cada um destes valores.

Foi realizado ensaio com as seguintes amostras: 1) tendões somente suturados com fio de sutura; 2) tendões suturados e parcialmente envolvidos com a membrana de PLDLA-co-TMC. Cada amostra teve 10 tendões, submetidas às mesmas condições de umidade $(50 \%)$ e temperatura $\left(25^{\circ} \mathrm{C} \pm 2\right)$.

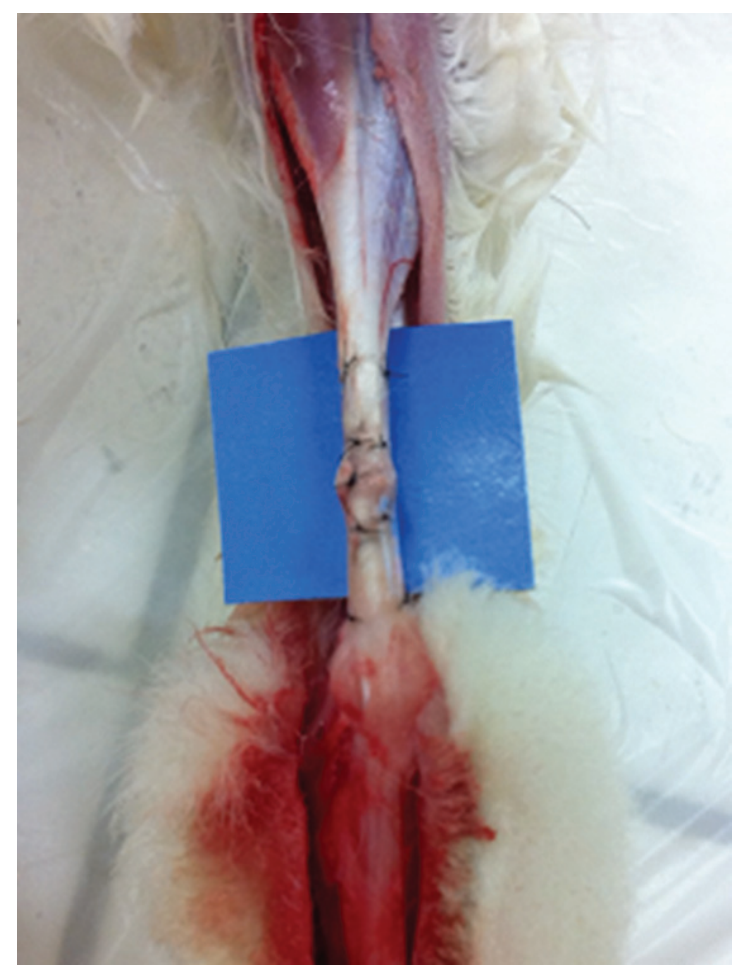

Figura 3. Aspecto macroscópico do tendão suturado com o terpolímero PLDLA-TMC. 


\section{Retirada do material para análise histológica}

Os animais do grupo B foram sacrificados após três semanas de implante com overdose de anestésico, por inalação de Halotano (AVMA Guidelines on Euthanasia), o coelho foi posicionado em decúbito ventral horizontal e o Tendão calcâneo foi cuidadosamente dissecado e ressecado. O seguimento do tendão era compreendido da junção musculotendínea até inserção, para possibilitar fixação adequada aos acessórios da maquina universal de ensaio. Os tendões designados a analise histológica foram seccionados $1,0 \mathrm{~cm}$ proximal e $0,5 \mathrm{~cm}$ distal ao local da sutura.

Os tendões foram examinados cuidadosamente realizando-se a avaliação macroscópica dos reparos obtidos e colocados imediatamente em solução de Formol 10\% para fixação por um período de 24 horas, em recipientes de vidro, individualmente identificados, que mantém a integridade dos tecidos após a morte.

\section{Avaliação macroscópica}

A análise macroscópica foi realizada em três parâmetros:

- Reparação - quanto à cicatrização propriamente dita do defeito;

- Continuidade - avaliação da organização e disposição das fibras colágenas;

- Aderência - avaliação durante a retirada do tendão.

\section{Análise histológica}

Os tendões Calcâneos retirados mediam em média $5 \mathrm{~cm}$ de comprimento. Os seguimentos, após fixação e devida identificação, foram macroscopicamente examinados e observou-se presença de fibras musculares e maior espessura numa das extremidades, esta foi considerada como proximal. A seguir cada uma das peças cirúrgicas foi seccionada em 3 porções (A, B, C) e a porção distal de cada um dos segmentos, foi pintada com nanquim. Então cada porção foi seccionada longitudinalmente, resultando em duas metades, que foram incluídas no mesmo bloco, permitindo uma visão completa do segmento. A coloração de nanquim permanece após o processamento histológico do material e não interfere na visualização microscópica. Após a secção do material, retiraram-se os fragmentos de fio cirúrgico contidos no interior das secções. $\mathrm{O}$ fio, no caso não reabsorvível, teve que ser retirado cuidadosamente, com o intuito de não traumatizar o tecido e tornar possível a secção histológica no micrótomo de parafina.

Para cada animal, resultaram três lâminas (A, B, C) de cada membro e com a correta ordenação dos seguimentos (Figura 4).

\section{Embebição em parafina}

As amostras foram submetidas aos seguintes processos: lavagem; desidratação em soluções crescentes de etanol; diafanização em etanol absoluto/xilol na proporção de 1:1 por 30 minutos, em seguida xilol puro por 30 minutos; embebição em xilol/parafina (HistosecMerck) a $60{ }^{\circ} \mathrm{C}$ na proporção 1:1 por 30 minutos; seguida
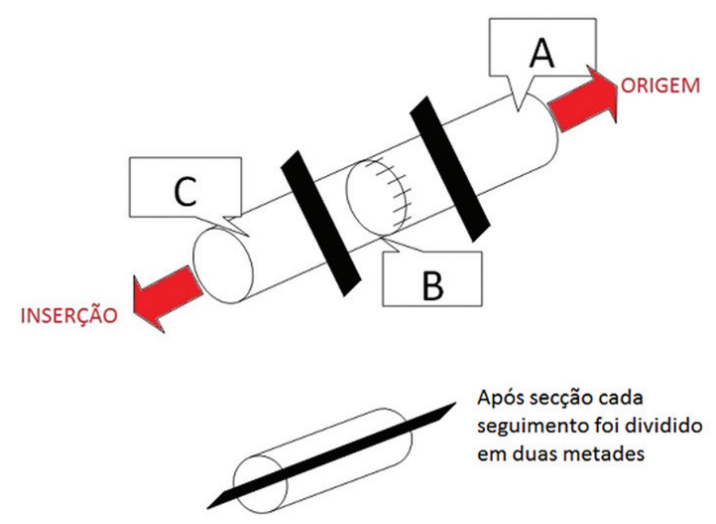

Figura 4. Esquema da secção dos seguimentos do tendão.

de parafina pura por 3 horas e inclusão em parafina líquida à temperatura ambiente.

Após estas etapas, o material foi colocado em formas de aproximadamente cinco $\mathrm{cm}^{3}$ e preenchido com parafina a $60{ }^{\circ} \mathrm{C}$, formando blocos. Esses blocos de parafina contendo o material incluído foram deixados em repouso durante 24 horas em temperatura ambiente para o endurecimento da mesma.

Os cortes histológicos foram realizados em micrótomo Leica ${ }^{\circledR}$ RM2245 com espessura de $5 \mu \mathrm{m}$ em secções no plano sagital, contendo o Tendão calcâneo inteiro; prosseguiu-se à coloração com Hematoxilina e Eosina, uma técnica bem estabelecida para a avaliação histológica, que permitiu a identificação de fibras colágenas, um dos principais atributos do tecido recémformado.

As lâminas foram analisadas e fotografadas em microscópio óptico com luz polarizada (Eclipse E800 - Nikon®).

\section{Avaliação microscópica}

No exame histológico qualitativo das secções do Tendão calcâneo, a atenção foi dirigida particularmente para os seguintes elementos:

1 qualidade da cicatrização e disposição das fibras colágenas;

2 avaliação da aderência nos tecidos vizinhos;

As lâminas, previamente identificadas, foram analisadas com relação à atividade fibroblástica, à deposição de colágeno e à vascularização no sitio da lesão, comparando o lado direito e esquerdo em cada animal.

\section{Resultados e Discussão}

\section{Caracterização membrana}

\section{GPC}

Através da cromatografia de permeação em gel foram obtidos resultados de massa molar média em número $(\mathrm{Mn})$, massa molar em massa (Mw) e polidispersividade (IP) do PLDLA-TMC empregado na obtenção da membrana. Os dados encontrados foram: $\mathrm{Mw}=206000 \mathrm{~g} / \mathrm{mol}$; $\mathrm{Mn}=195000 \mathrm{~g} / \mathrm{mol}$ e IP = 1,1, e demonstram que o terpolimero empregado no trabalho apresenta alta massa 
molar, como é o requerido para um grande número de aplicações que envolvem desde fixadores de fraturas ate arcabouços poliméricos, situações que requerem matérias com boas propriedades mecânicas, o que este atrelado a materiais de alta massa molar ${ }^{[14]}$.

DSC

A Figura 5 apresenta a análise de DSC para o terpolimero PLDLA-TMC sendo observado somente temperatura de transição vítrea $\left(\mathrm{T}_{\mathrm{g}}\right)$, demonstrando se tratar de um material amorfo. A maior flexibilidade apresentada pela membrana de PLDLA-TMC, em função da presença das unidades de TMC na cadeia polimérica, reflete na ligeira queda no valor de $\mathrm{Tg}$ apresentado pelo

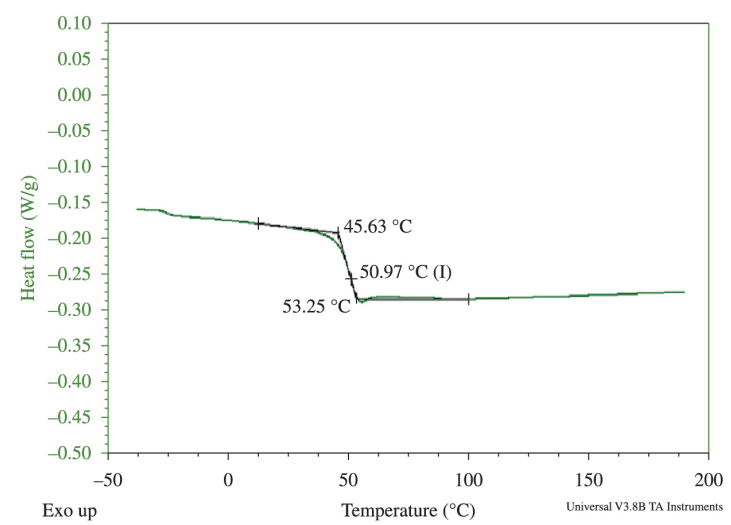

Figura 5. DSC do $2^{\circ}$ aquecimento do PLDLA-TMC.

Tabela 1. Valores da tensão máxima na ruptura das amostras de tensão suturados com membrana de PLDLA-co-TMC e sem membrana.

\begin{tabular}{lccc}
\hline \multicolumn{1}{c}{ Tendão } & $\begin{array}{c}\text { Número de } \\
\text { amostras }\end{array}$ & $\begin{array}{c}\text { Tensão } \\
\text { máxima } \\
(\mathbf{M P a})\end{array}$ & $\begin{array}{c}\text { Desvio } \\
\text { padrão }\end{array}$ \\
\hline Sem membrana & 10 & 4,16 & $\pm 1,34$ \\
Com membrana & 10 & 4,36 & $\pm 0,63$ \\
PLDLA-co-TMC & & & \\
\hline
\end{tabular}

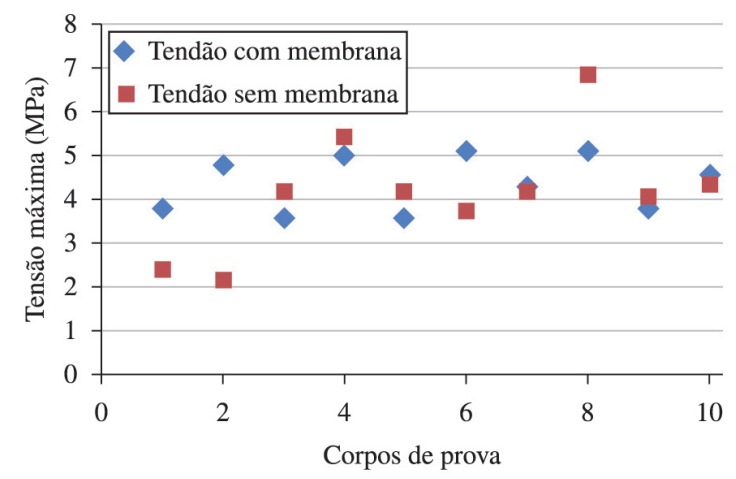

Figura 6. Valores da Tensão máxima na ruptura das amostras de tensão suturados com membrana de PLDLA-co-TMC e sem membrana, para os 10 corpos de prova utilizados nos ensaios mecânico de tração. terpolimero, $50{ }^{\circ} \mathrm{C}$, se comparado ao PLDLA (de $58{ }^{\circ} \mathrm{C}$ ) estudado por Motta ${ }^{[15]}$.

\section{Ensaio mecânico de tração}

O comportamento mecânico do terpolímero PLDLAco-TMC na forma de membrana foi avaliado como recobrimento de tendão de coelhos. A Tabela 1 apresenta os dados obtidos do ensaio de tração realizado em tendões de coelho, os quais foram submetidos a duas situações: numa delas o tendão suturado foi recoberto com a membrana do terpolímero, enquanto que na outra situação o tendão somente foi suturado. Dessa forma, tentou-se avaliar se a presença da membrana no tendão suturado agia de forma a induzir uma maior resistência neste tecido em recuperação.

O Gráfico (Figura 6) é referente às tensões de cada corpo de prova (tendão com ou sem membrana) analisado:

Através dos resultados do ensaio mecânico de tração verifica-se que a resistência mecânica dos tendões recobertos com a membrana do terpolímero é praticamente a mesma dos tendões não revestidos pela membrana, levando-se em consideração os valores dos desvios padrões.

\section{Análise histológica}

No grupo em estudo, isto é, tendão com a presença de membrana, o aspecto histológico encontrado foi semelhante em todos os animais, ou seja, todos apresentavam a formação de fibras colágenas na região da sutura do tendão e cicatrização. A análise histológica do seguimento identificado como A (Figura 4), ou proximal, observou-se presença de área com fibrose acentuada e desorganização, colágeno denso e áreas "vazias" resultantes da presença do fio cirúrgico que havia sido retirado (Figura 7). Havia também escassa reação do tipo corpo estranho e presença de restos da membrana. Em todos os casos, sem exceção, nos seguimentos identificados como B (Figura 4), a análise histológica mostrou a presença de fibras colágenas bem organizadas, orientadas longitudinalmente, bem ordenadas, em tudo semelhantes a um tendão normal (Figura 8). Ao redor, observou-se tecido conjuntivo frouxo, porém não detectamos uma cápsula, sendo que esta, usualmente é de difícil visualização. Às vezes, observamos pequenas falhas resultante da presença de restos de fio cirúrgico. Em continuidade, no seguimento C (Figura 4), na sua porção mais proximal havia perfeita contiguidade do tendão e na porção espessada observa-se um aspecto semelhante ao descrito em relação à primeira porção com presença de fibrose e cicatriz desorganizada. $\mathrm{O}$ grupo controle teve resultado semelhante, porém com tendões menos espessos em relação ao seguimento B e fibras colágenas discretamente menos organizadas, quando comparamos aos seguimentos com membrana (Figura 9).

Uma das grandes limitações no tratamento e reabilitação de pacientes com lesão tendinosa reside no fato desse processo de reparação ser lento, necessitando que o tendão seja submetido à tensão, durante a fase de reparação, para evitar a formação de cicatrizes e adesão com o tecido adjacente ${ }^{[3]}$. O estudo procurou avaliar o possível benefício que um novo polímero com melhores 


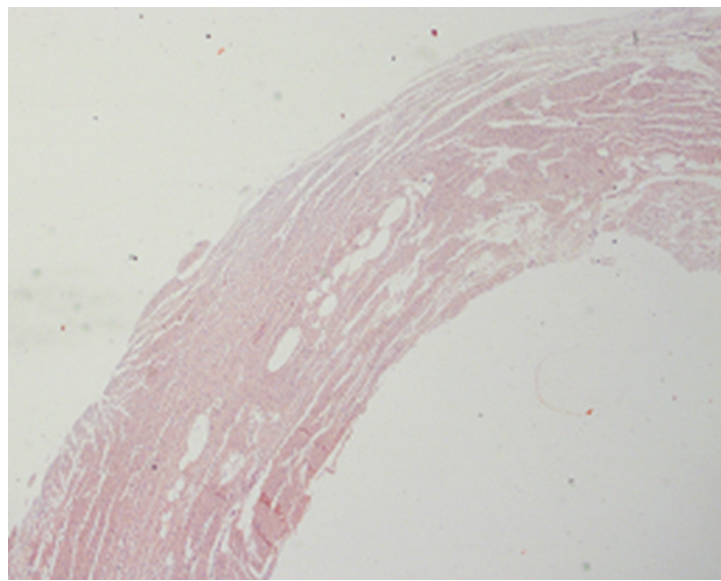

Figura 7. Fotomicrografia da região de reparação do tendão sem uso do polímero PLDLA-TMC, HE, X 20.

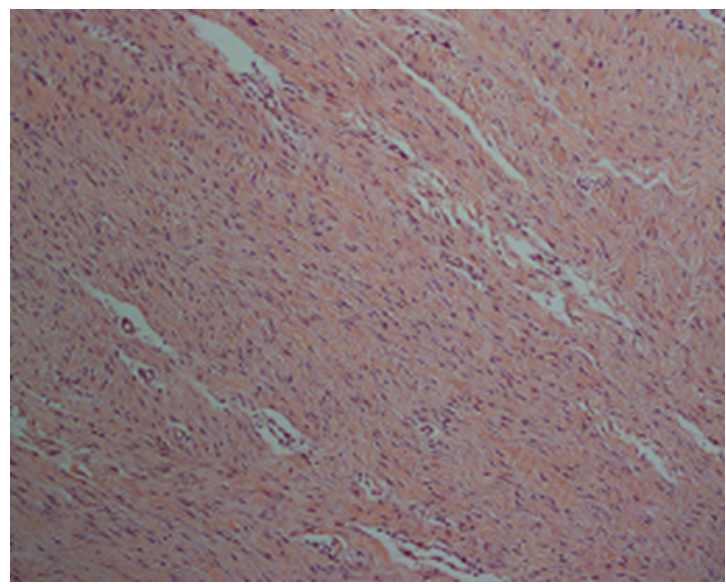

Figura 8. Fotomicrografia da região de reparação do tendão com uso do polímero PLDLA-TMC, HE, X 100.

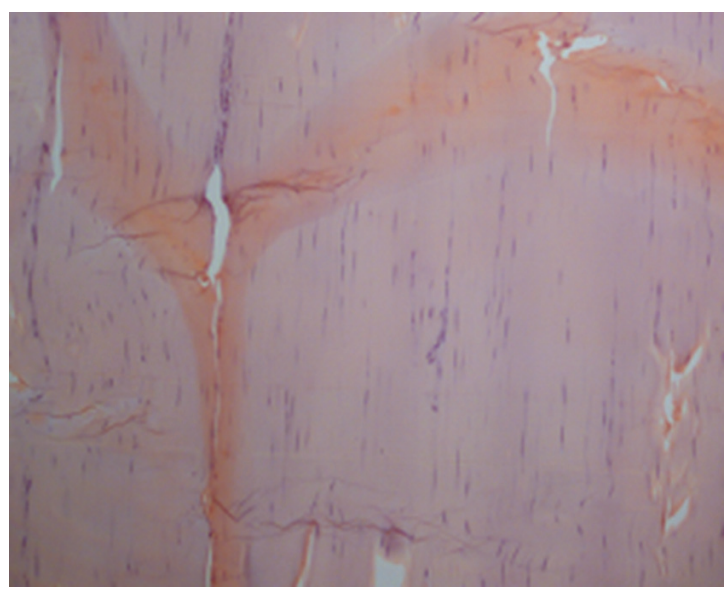

Figura 9. Fotomicrografia da região do tendão sem lesão, HE, X 100 .

propriedades físicas e químicas poderia propiciar à área de reparo do tendão ${ }^{[10-12]}$

O polímero PLDLA-TMC, o qual foi usado neste estudo, apresenta melhores resultados de resistência e elasticidade do que outros produtos, que já foram usados em outros estudos em coelhos, pois apresenta uma maior massa molar e isso possibilita essa melhora nos parâmetros citados $^{[11,16,17]}$. O uso do polímero PLDLA-TMC como protetor da área de sutura do tendão, proporcionou uma melhor cicatrização, ou seja, melhor organização das fibras colágenas e menor aderência que foi avaliada macro e microscopicamente. Quanto à resistência mecânica da sutura com o uso do terpolimero PLDLA-TMC, foi evidenciado um ganho pouco significativo.

\section{Conclusões}

O estudo in vivo demonstrou que a utilização da membrana do terpolimero PLDLA-TMC envolvendo a sutura do tendão é promissora, pois proporcionou melhora no seu processo de reparação, evidenciada pela observação da melhor organização das fibras colágenas no tendão em recuperação. Não houve diferença significativa quanto à resistência mecânica da sutura com o uso do Terpolímero. Foi ainda verificado que a presença da membrana do polímero proporcionou uma menor aderência na cirurgia da retirada do tendão e menor formação de tecido cicatricial na avaliação histológica.

\section{Referências Bibliográficas}

1. Józsa, L. \& Kannus, P. - "Overuse Injuries of Tendons, Human Tendons: Anatomy, Physiology, and Pathology", p.164 (1997).

2. Lin, T.W., Cardenas, L. \& Soslowsky, J. - "Biomechanics of Tendon Injury and Repair", p. 865-77 (2004).

3. James, R., Kesturu, G., Balian, G. \& Chhabra, B. - J. Hand Surg. Am., 33A, p.102 (2008). PMid:18261674. http:// dx.doi.org/10.1016/j.jhsa.2007.09.007

4. Junqueira, L. C. \& Carneiro, J. - "Tecido conjuntivo. Histologia Básica”, 10. ed., Guanabara Koogan, Rio de Janeiro (2004).

5. Carvalho Junior, A. E. \& Imamura, M. - "Lesões Tendíneas. Ortopedia e Traumatologia: Princípios e Prática”, 3. ed., Artmed, Porto Alegre (2003).

6. Beredjiklian, P. K. - J. Bone J. Surg. Am., 85A, p.539 (2003).

7. Zhao, H.; et al. - Chin. Med., 126, p.729 (2013).

8. Gigante, A.; et al. - J. Orthop. Res., 31, p.738 (2013). PMid:23335065. http://dx.doi.org/10.1002/jor.22270

9. Nilsson-Helander, K.; et al. - Am. J. Sports Med., 38, p.2186 (2010). PMid:20802094. http://dx.doi. org/10.1177/0363546510376052

10. Badia, A. - "Use of Bioresorbable Polylactide Sheet (OrthoWrap ${ }^{\circledR}$ ) for Reduction of Soft Tissue Attachments in Hand Surgery", Clinical Data Series in Bioresorbable Technologies (2007).

11. Pihlajamäki, H.; et al. - J. Orthop. Res., 26, p.264 (2008). PMid:17902177. http://dx.doi.org/10.1002/jor.20504

12. Pêgo, A. P.; et al. - J. Biomed. Mater. Res. A. (2003).

13. Motta, A. C. \& Duek, E. A. R. - "Sintese de terpolímero bioreabsorvivel para aplicação médica", $\mathrm{Br}$ PI 020110049277 (2011).

14. Gogolewski, S. - Injury Int. J. Care Injured, 31, p.28 (2000). http://dx.doi.org/10.1016/S0020-1383(00)80020-0 
15. Motta, A. C "Síntese e caracterização de dispositivos de poli( L-co-DL ácido-lático). Estudo da degradação in vitro e in vivo", Tese de doutorado (2007).

16. Gogolewski, S. \& Jovanovic, M. - Polym. Degrad. Stabil, 40, p.313 (1993). http://dx.doi.org/10.1016/01413910(93)90137-8
17. Barbanti, S., Duek, E. A. R. \& Zavaglia, C. - Polímeros, 15, p.13 (2005). http://dx.doi.org/10.1590/S010414282005000100006

Enviado: 22/04/13 Reenviado: $23 / 11 / 13$ Aceito: $12 / 12 / 13$ 